\title{
DESIGN FOR ADDITIVE MANUFACTURING: IS IT AN EFFECTIVE ALTERNATIVE? PART 2 - COST EVALUATION
}

\author{
FRANCO CONCLI $^{1}$, MARGHERITA MOLINARO ${ }^{2}$ \& ELEONORA RAMPAZZO ${ }^{1}$ \\ ${ }^{1}$ Free University of Bolzano/Bozen, Faculty of Science and Technology, Italy \\ ${ }^{2}$ University of Udine, Polytechnic Department of Engineering and Architecture, Italy
}

\begin{abstract}
Additive Manufacturing (AM) is becoming a more and more widespread (and trendy) approach. Its flexibility and capability to manufacture any topology has opened new possibilities: AM could lead to significant performance improvements thanks to the exploitation of lattice or reticular structures as partial replacement of the traditional solid design. The potential of this technology knows no bounds. However, in the real world, the lower performances of the materials and the high manufacturing costs significantly restrict the fields of application for which the adoption of AM results effective. In this context, the mechanical static and fatigue properties of a 17-4 PH Stainless Steel produced via AM were experimentally measured and compared with those of the wrought material to quantify the performance reduction. Based on these data, three components, namely a hip prosthesis, a blow plastic bottle die, and an automotive gear were selected as representative examples to show the pros and contra of AM. The three components were chosen because they belong to three quite dissimilar fields and are produced in different batch sizes. The three original designs were specifically optimized for AM by means of Finite Element (FE) Simulations. The new solutions fulfil the strength requirements of the original parts showing at the same time reduced weights and inertias. The traditional and new designs were compared in terms of production times and costs to quantify the real benefits of AM for different applications.
\end{abstract}

Keywords: additive manufacturing, FEM, optimization.

\section{INTRODUCTION}

Based on the optimization of the design carried out in the first part of this work, in this second paper an economical/feasibility analysis of the optimized solutions for each of the analysed case studies ("Hip Prosthesis", "Bottle Blowing Mold" and "Automotive Gear") is made. To better highlight drawbacks and benefits of the Additive Manufacturing (AM), three solutions for each case study were analysed. Specifically, the original design was virtually manufactured with traditional operations, relying on the Computer Numerical Control (CNC) machine, and with Selective Laser Melting (SLM) machine. These two solutions were compared with the optimized counterparts relying on a lattice internal structure, manufactured with the SLM machine.

The outcomes of the analysis are aimed at showing the effectiveness of the new technology, both in terms of production costs and times.

\section{COST CALCULATION PROCEDURE}

In the literature, different costing techniques, as well as different cost drivers and areas of applications, have been used to estimate unit costs [1], [2]. Material costs, labor costs and overhead costs, which include all cost elements other than the previous two, are typically considered in the cost calculation techniques [3], [4]. What differs among the various models proposed in the literature is not only the approach adopted for the calculation (i.e., task-based vs. level-based), but also the number and type of cost drivers, beyond labor and material 
costs, considered in the analysis (e.g., machine, electricity, set-up, tooling, inventory, logistics costs etc.) [1].

In line with other studies comparing total costs in traditional and additive manufacturing environments [5]-[7], in this study a task-based approach using a process-oriented cost model was adopted. Thus, only the production process was included in the calculations. Moreover, pre-processing and part manufacturing were considered separately. These phases were selected to properly represent different cost centers, thus facilitating the calculation and making it easier to apply the model in other contexts [8].

Each phase was associated to a certain number of cost drivers. The pre-processing phase, which deals with all the activities that precede the effective production, included all the costs for the preparation of CAM software. The part manufacturing phase, which represents the effective production, included instead all costs related to material, labor, machines, tools, and electricity. The calculation of these cost drivers varied according to the manufacturing type.

As the above overview shows, the model did not aim to calculate the effective total cost of the two solutions, but only the sum of cost drivers that differ between them. Accordingly, only the factors directly affecting the part cost were considered, in line with [5] and [6]. All the other costs, such as administrative overhead, logistics, rental costs, etc. [9], [10], can be considered invariant among traditional and additive manufacturing environments and, therefore, they were not taken into account in the model. Furthermore, as highlighted in previous studies [10], [11], the abovementioned terms have an effect on the total cost limited to $10 \%$. Therefore, their inclusion in the calculations would not significantly affect the results.

Before providing a detailed description of the cost drivers, it is worth clarifying the assumptions at the basis of our calculation model. First of all, it was assumed that the manufacturing plant works 16 hours per day, 5 days per week and 48 weeks per year, with a consequent total productive number of hours per year equal to $3,840 \mathrm{~h} / \mathrm{year}$. Second, it was assumed that the manufacturing plant is located in Italy and thus this country was used as a reference for all the estimations. In particular, we selected a medium-sized Italian company operating in the engineering sector to collect reliable information on cost drivers (e.g., hourly costs of labor and electricity, material costs, tools costs, etc.), as well as to estimate the time needed for the various activities (e.g., set-up time). Finally, the straight-line depreciation technique was adopted to calculate the machine hourly cost, in line with [5], [6], [9]. This required the estimation of the total cost and the economic life of the production machines. Dividing the total cost by the number of useful life hours, the machine cost per hour, which was taken into consideration for both set-up and production activities, could be derived.

The following paragraphs explain how the costs were estimated in the two manufacturing environments.

\subsection{Cost calculation for traditional manufacturing}

In traditional manufacturing, the production consists of two main phases processed on the same CNC machine. The first phase (i.e., roughing) subtracts the waste material from an initial rough block volume of steel to obtain the rough shape of the product. Starting from this, the second phase (i.e., surface finishing) finishes the piece by removing a further layer of material to obtain the final required quality of the product.

The six cost drivers used for the calculation of the total cost in this manufacturing environment are shown and explained in Table 1.

The preparation of CAM software represents the first cost item, calculated multiplying the hourly cost of the programming by the time needed for such activity. The hourly cost of 
the programming was obtained considering both software cost and labor cost of programming, while the working time was estimated taking into consideration that both roughing and surface finishing phases require the development of a customized program.

Table 1: Cost calculation procedure for traditional manufacturing.

\begin{tabular}{|c|c|c|c|}
\hline \multirow{3}{*}{$\begin{array}{l}\text { CAM } \\
\text { programming } \\
\text { cost }\end{array}$} & $\begin{array}{l}\text { Hourly cost for CAM } \\
\text { programming }\end{array}$ & $€ / \mathrm{h}$ & $\mathrm{PC}$ \\
\hline & Programming time & $\mathrm{h}$ & $\mathrm{PT}$ \\
\hline & Total CAM programming cost & $€$ & $\mathrm{CAM}=\mathrm{PC} \cdot \mathrm{PT}$ \\
\hline \multirow{4}{*}{ Material cost } & Rough block volume & $\mathrm{mm}^{3}$ & $\mathrm{~V}$ \\
\hline & Rough block weight & $\mathrm{kg}$ & $\mathrm{W}=0.008 / 1,000 \cdot \mathrm{V}$ \\
\hline & Unit material cost & $€ / \mathrm{kg}$ & $\mathrm{UC}$ \\
\hline & Total material cost & $€ / \mathrm{pc}$ & $\mathrm{MAT}=\mathrm{W}^{*} \mathrm{UC}$ \\
\hline \multirow{5}{*}{ Labor cost } & CNC manufacturing time & $\min / \mathrm{pc}$ & MT \\
\hline & Worker time for manufacturing & $\mathrm{min} / \mathrm{pc}$ & $\mathrm{WT}=0.1 \cdot \mathrm{MT}$ \\
\hline & Worker time for machine set-up & $\mathrm{min} / \mathrm{pc}$ & ST \\
\hline & Hourly labor cost & $€ / \mathrm{h}$ & $\mathrm{LC}$ \\
\hline & Total labor cost & $€ / \mathrm{pc}$ & $\mathrm{LAB}=(\mathrm{WT}+\mathrm{ST}) \cdot \mathrm{LC} / 60$ \\
\hline \multirow{3}{*}{ Tool cost } & Tool useful life & $\min$ & $\mathrm{TL}$ \\
\hline & Unit tool cost & $€ /$ tool & $\mathrm{TC}$ \\
\hline & Total tool cost & $€ / \mathrm{pc}$ & $\mathrm{TOO}=(\mathrm{MT} / \mathrm{L}) \cdot \mathrm{TC}$ \\
\hline \multirow{4}{*}{$\begin{array}{l}\mathrm{CNC} \\
\text { machine cost }\end{array}$} & Working hours per year & $\mathrm{h} /$ year & $\mathrm{H}$ \\
\hline & CNC machine useful life & year & ML \\
\hline & Total CNC machine cost & $€$ & $\mathrm{MC}$ \\
\hline & Total CNC machine cost & $€ / \mathrm{pc}$ & $\begin{array}{l}\mathrm{MCC}=(\mathrm{ST}+\mathrm{MT}) \cdot \\
(\mathrm{MC} / \mathrm{H} / \mathrm{ML} / 60)\end{array}$ \\
\hline \multirow{3}{*}{ Energy cost } & CNC consumed electrical power & $\mathrm{kW}$ & P1 \\
\hline & Hourly energy cost & $€ / \mathrm{kWh}$ & $\mathrm{EC}$ \\
\hline & Total energy cost & $€ / \mathrm{pc}$ & $\mathrm{ENE}=(\mathrm{MT} / 60) \cdot \mathrm{P} 1 \cdot \mathrm{EC}$ \\
\hline \multirow[b]{2}{*}{ Total cost } & Production volume & $\mathrm{pc}$ & $\mathrm{N}$ \\
\hline & Total unit cost & $€ / p c$ & $\begin{array}{l}\mathrm{C}=\mathrm{CAM}+\mathrm{N} \cdot(\mathrm{MAT}+ \\
\mathrm{LAB}+\mathrm{TOO}+\mathrm{MCC}+ \\
\mathrm{ENE})\end{array}$ \\
\hline
\end{tabular}

The material cost was instead computed considering the initial rough block volume of steel, from which to subtract the waste material. The dimensions of the initial block were chosen according to the object to be manufactured (i.e., hip prosthesis, bottle blowing mold or automotive gear) and its weight was estimated by supposing a density of $8 \mathrm{~g} / \mathrm{cm}^{3}$. Multiplying the weight of the block by the cost of a unit weight of material, provided by a supplier of the reference company, the total material cost was obtained.

For the labor cost, the time needed for the operator to monitor the machine (i.e., manufacturing activity) and that needed to load and unload the pieces from the machine (i.e., set-up activity) was taken into account in the calculations. The former was defined as the $10 \%$ of the total manufacturing time and the latter was estimated with the support of the reference company, which also provided the data of the hourly labor cost. The total labor cost was simply given by the product between the total working time of the operator and the hourly labor cost. 
The traditional $\mathrm{CNC}$ machine requires a tool for the manufacturing. After the estimation of unit tool cost and tool useful life (using the Taylor's formula), the total tool cost was calculated multiplying the number of tools needed for the manufacturing of one single piece by the unit tool cost.

The machine cost was calculated considering the money spent to buy the machine, its useful life and the expected working hours per year, whose product provided the hourly machine cost. This latter cost, multiplied by the total time during which the machine is expected to be employed, provided an estimation of total machine cost per piece.

Finally, to estimate the energy cost, electrical power consumption was multiplied by the hourly energy cost, provided again by the reference company.

Obviously, to calculate the total cost of a single piece, variable and fixed costs were distinguished. The only fixed cost item in our analysis was represented by the programming cost, whose value is independent from the number of manufactured units. Thus, the total cost was calculated by multiplying all variable costs by the hypothesized volume and summing the result to the CAM programming cost.

For a more complete understanding of the calculation process, an overview of how the total manufacturing time was calculated is shown in Table 2. In particular, the table distinguishes between roughing and surface finishing phases. Each of them has different waste volumes (i.e., volumes to be subtracted from the block) and different working speeds. By summing the time needed to carry out each phase, the total manufacturing time, namely the time during which a single piece is processed on the CNC machine, was obtained.

Table 2: Calculation procedure for manufacturing time.

\begin{tabular}{llll}
\hline \multirow{2}{*}{$\begin{array}{l}\text { Roughing } \\
\text { data }\end{array}$} & Waste volume roughing & $\mathrm{mm}^{3}$ & $\mathrm{~S}$ \\
\cline { 2 - 4 } & MRR roughing & $\mathrm{mm}^{3} / \mathrm{min}$ & MRRS \\
\hline $\begin{array}{l}\text { Surface } \\
\text { finishing } \\
\text { data }\end{array}$ & Waste volume surface finishing & $\mathrm{mm}^{3}$ & $\mathrm{~F}$ \\
\cline { 2 - 4 } & MRR surface finishing & $\mathrm{mm}^{3} / \mathrm{min}$ & $\mathrm{MRRF}$ \\
\hline & CNC manufacturing time & $\mathrm{min} / \mathrm{pc}$ & $\mathrm{MT}=\mathrm{S} / \mathrm{MRRS}+\mathrm{F} / \mathrm{MRRF}$ \\
\hline
\end{tabular}

\subsection{Cost calculation for AM}

In AM, the production consists of two main phases, processed on different machines. In the first phase, the SLM machine is used, and the rough shape of the product is obtained. As in traditional manufacturing, this phase is followed by a surface finishing, carried out with a $\mathrm{CNC}$ machine, which finishes the piece by filing a further layer of material to obtain the final configuration of the product.

The cost items used for the calculation are reported in Table 3. The procedure was similar to the one described for traditional manufacturing, but with some differences.

First of all, the machine cost was calculated for both CNC and SLM machines. For what concerns this latter, the speed time was estimated by checking several values provided by some SLM equipment suppliers regarding machines with specifications similar to the one used for the 17-4 PH SS samples. Starting from this value and considering the volume to be produced, the total manufacturing time on SLM machine could be calculated. Finally, the overall machine cost was estimated considering, as for traditional manufacturing, the money spent to buy the machine, its useful life, and the expected working hours per year. 
Table 3: Cost calculation procedure for AM.

\begin{tabular}{|c|c|c|c|}
\hline \multirow{3}{*}{$\begin{array}{l}\text { CAM } \\
\text { programming } \\
\text { cost }\end{array}$} & Hourly cost for CAM programming & $€ / \mathrm{h}$ & $\mathrm{PC}$ \\
\hline & Programming time & $\mathrm{h}$ & PT \\
\hline & Total CAM programming cost & $€$ & $\mathrm{CAM}=\mathrm{PC} * \mathrm{PT}$ \\
\hline \multirow{4}{*}{ Material cost } & Rough piece volume & $\mathrm{mm}^{3}$ & $\mathrm{~V}$ \\
\hline & Rough piece weight & $\mathrm{kg}$ & $\mathrm{W}=0.008 / 1,000 \cdot \mathrm{V}$ \\
\hline & Unit material cost & $€ / \mathrm{kg}$ & $\mathrm{UC}$ \\
\hline & Total material cost & $€ / \mathrm{pc}$ & $\mathrm{MAT}=\mathrm{W} * \mathrm{UC}$ \\
\hline \multirow{5}{*}{ Labor cost } & CNC manufacturing time & $\min / \mathrm{pc}$ & MT \\
\hline & Worker time for manufacturing & $\mathrm{min} / \mathrm{pc}$ & $\mathrm{WT}=0.1 * \mathrm{MT}$ \\
\hline & Worker time for machine set-up & $\min / \mathrm{pc}$ & ST \\
\hline & Hourly labor cost & $€ / \mathrm{h}$ & $\mathrm{LC}$ \\
\hline & Total labor cost & $€ / \mathrm{pc}$ & $\mathrm{LAB}=(\mathrm{WT}+\mathrm{ST}) \cdot \mathrm{LC} / 60$ \\
\hline \multirow{3}{*}{ Tool cost } & Tool useful life & Min & $\mathrm{TL}$ \\
\hline & Unit tool cost & $€ /$ tool & $\mathrm{TC}$ \\
\hline & Total tool cost & $€ / \mathrm{pc}$ & $\mathrm{TOO}=(\mathrm{MT} / \mathrm{L}) \cdot \mathrm{TC}$ \\
\hline \multirow{4}{*}{$\begin{array}{l}\text { CNC machine } \\
\text { cost }\end{array}$} & Working hours per year & $\mathrm{h} /$ year & $\mathrm{H}$ \\
\hline & CNC machine useful life & Year & ML \\
\hline & Total CNC machine cost & $€$ & MC \\
\hline & Total CNC machine cost & $€ / \mathrm{pc}$ & $\begin{array}{l}\mathrm{MCC}=(\mathrm{ST}+ \\
\mathrm{MT}) \cdot(\mathrm{MC} / \mathrm{H} / \mathrm{ML} / 60)\end{array}$ \\
\hline \multirow{5}{*}{$\begin{array}{l}\text { SLM machine } \\
\text { cost }\end{array}$} & Speed SLM production & $\mathrm{cm}^{3} / \mathrm{h}$ & $\mathrm{SP}$ \\
\hline & SLM manufacturing time & $\min / \mathrm{pc}$ & $\mathrm{M}=\mathrm{V} / 1,000 / \mathrm{SP} \cdot 60$ \\
\hline & SLM machine useful life & Year & SL \\
\hline & Total SLM machine cost & $€$ & $\mathrm{SC}$ \\
\hline & Total SLM machine cost & $€ / \mathrm{pc}$ & $\mathrm{MSC}=\mathrm{M} \cdot(\mathrm{SC} / \mathrm{H} / \mathrm{SL} / 60)$ \\
\hline \multirow{4}{*}{ Energy cost } & CNC consumed electrical power & $\mathrm{kW}$ & P1 \\
\hline & SLM consumed electrical power & $\mathrm{kW}$ & $\mathrm{P} 2$ \\
\hline & Hourly energy cost & $€ / \mathrm{kWh}$ & EC \\
\hline & Total energy cost & $€ / \mathrm{pc}$ & $\begin{array}{l}\mathrm{ENE}=[(\mathrm{MT} / 60) \cdot \mathrm{P} 1+ \\
(\mathrm{M} / 60) \cdot \mathrm{P} 2] \cdot \mathrm{EC}\end{array}$ \\
\hline \multirow[b]{2}{*}{ Total cost } & Production volume & $\mathrm{pc}$ & $\mathrm{N}$ \\
\hline & Total unit cost & $€ / \mathbf{p c}$ & $\begin{array}{l}\text { C }=\text { CAM }+\mathbf{N}^{*}(\text { MAT }+ \text { LAB } \\
+ \text { TOO }+ \text { MCC }+ \text { MSC }+ \\
\text { ENE })\end{array}$ \\
\hline
\end{tabular}

For what concerns instead all the other cost items, the differences compared to traditional manufacturing included:

- the programming time, which was defined taking into consideration that only the surface finishing phase requires a customized program, while no programming is needed for SLM machine;

- the rough piece volume, which was equal to the final piece volume plus the small waste generated in the surface finishing phase; 
- the CNC manufacturing time, which included only the time needed for the surface finishing phase;

- the worker time for machine set-up, which included the time needed to move the pieces from the SLM to the CNC machine and to unload the final piece from this latter at the end of the production; no labor was considered for the SLM production; and

- the total energy cost, which was calculated considering both SLM and CNC energy consumptions, as shown in Table 3.

\section{COST ANALYSIS AND RESULTS}

Using the cost models described in the previous section, we estimated the unit cost of the three products (i.e., hip prosthesis, bottle blowing mold or automotive gear) in three potential situations: use of traditional manufacturing, use of AM and use of AM with geometry optimization through lattice internal structure. The main cost advantages of this latter case are the need of a lower volume of material, which results into a lower material cost, and the consequent reduction of SLM manufacturing time, which in turn decreases the machine cost for the product.

The total unit cost of bottle blowing mold and automotive gear was also distinguished for different batch volumes. Indeed, while the hip prosthesis can be considered a highly customized product manufactured in single batches, the other two components are typically produced with more numerous volumes. In particular, a batch of 10 pieces was considered for the bottle blowing mold and one of 1,000 pieces was hypothesized for the automotive gear. As we previously highlighted, a more numerous batch allows to reduce the unit cost of programming.

The manufacturing time for the $\mathrm{CNC}$ machine required the estimation of the Material Removal Rate (MRR) and waste volumes. Relying on the reference company's data, the MRR roughing was set at $72,000 \mathrm{~mm}^{3} / \mathrm{min}$ for hip prosthesis and bottle blowing mold and at $18,000 \mathrm{~mm}^{3} / \mathrm{min}$ for automotive gear. The MRR surface finishing was instead estimated as $1,800 \mathrm{~mm}^{3} / \mathrm{min}$ for hip prosthesis and bottle blowing mold and as $450 \mathrm{~mm}^{3} / \mathrm{min}$ for automotive gear. The waste volumes were calculated considering the difference between rough block/piece volumes and the final expected volume of each product. They are shown in Table 4, together with the resulting CNC manufacturing times. These latter were calculated with the formula reported in Table 2 and considering that, while in traditional manufacturing the $\mathrm{CNC}$ machine is used for both roughing and surface finishing phases, with significant waste volumes, in AM the CNC machine is employed only for surface finishing.

Table 4: Waste volumes and CNC manufacturing time.

\begin{tabular}{lcccc}
\hline & & $\begin{array}{c}\text { Hip } \\
\text { prosthesis }\end{array}$ & $\begin{array}{c}\text { Bottle } \\
\text { blowing mold }\end{array}$ & $\begin{array}{c}\text { Automotive } \\
\text { gear }\end{array}$ \\
\hline Waste volume roughing & $\mathrm{mm}^{3}$ & $381,051.64$ & $1,635,734.08$ & $22,835.51$ \\
\hline Waste volume surface finishing & $\mathrm{mm}^{3}$ & 778.97 & $81,796.37$ & $1,082.67$ \\
\hline $\begin{array}{l}\text { CNC manufacturing time for } \\
\text { traditional manufacturing }\end{array}$ & $\mathrm{min} / \mathrm{pc}$ & 5.73 & 68.16 & 3.67 \\
\hline $\begin{array}{l}\text { CNC manufacturing time for } \\
\text { additive manufacturing }\end{array}$ & $\mathrm{min} / \mathrm{pc}$ & 0.43 & 45.44 & 2.41 \\
\hline
\end{tabular}

The detailed results of the cost calculations for traditional manufacturing and AM are shown in Tables 5 and 6 respectively. A summary of the results for the three components is further depicted in Figs 1-3. For what concerns AM with geometry optimization, the 
calculation of the rough piece volume was carried out by considering the results obtained in the optimization activity in terms of average cell volumes and cell box volumes. These values were equal to $28 \mathrm{~mm}^{3}$ and $35.9 \mathrm{~mm}^{3}$ respectively.

Starting from Tables 5 and 6 data, we also carried out some sensitivity analysis. In particular, we recalculated the total unit cost of the three products first by modifying machines purchase costs and then unit material cost. The results were similar to those shown in the tables, giving support to their reliability.

For a more complete analyses of the various manufacturing solutions, we also compared the time needed to produce a single hip prosthesis, a bottle blowing mold and an automotive gear, distinguishing between different batch volumes (V). The results are shown in Table 7.

Table 5: Total unit cost for traditional manufacturing.

\begin{tabular}{|c|c|c|c|c|}
\hline & & $\begin{array}{l}\text { Hip } \\
\text { prosthesis }\end{array}$ & $\begin{array}{l}\text { Bottle blowing } \\
\text { mold }\end{array}$ & $\begin{array}{l}\text { Automotive } \\
\text { gear }\end{array}$ \\
\hline Hourly cost for CAM programming & $€ / \mathrm{h}$ & 40 & 40 & 40 \\
\hline Programming time & $\mathrm{h}$ & 4 & 8 & 1 \\
\hline Total CAM programming cost & $€$ & 160 & 320 & 40 \\
\hline Rough block volume & $\mathrm{mm}^{3}$ & 420,000 & $5,725,552.61$ & $76,969.02$ \\
\hline Rough block weight & $\mathrm{kg}$ & 3.36 & 45.80 & 0.62 \\
\hline Unit material cost & $€ / \mathrm{kg}$ & 3 & 3 & 3 \\
\hline Total material cost & $€ / \mathrm{pc}$ & 10.08 & 137.41 & 1.85 \\
\hline $\mathrm{CNC}$ manufacturing time & $\mathrm{min} / \mathrm{pc}$ & 5.73 & 68.16 & 3.67 \\
\hline Worker time for manufacturing & $\mathrm{min} / \mathrm{pc}$ & 0.57 & 6.82 & 0.37 \\
\hline Worker time for machine set-up & $\mathrm{min} / \mathrm{pc}$ & 5 & 5 & 3 \\
\hline Hourly labor cost & $€ / \mathrm{h}$ & 20 & 20 & 20 \\
\hline Total labor cost & $€ / \mathrm{pc}$ & 1.86 & 3.94 & 1.22 \\
\hline Tool useful life & $\min$ & 35 & 35 & 90 \\
\hline Unit tool cost & $€ /$ tool & 100 & 100 & 200 \\
\hline Total tool cost & $€ / \mathrm{pc}$ & 16.36 & 194.75 & 8.17 \\
\hline Working hours per year & $\mathrm{h} /$ year & 3,840 & 3,840 & 3,840 \\
\hline CNC machine useful life & year & 15 & 15 & 15 \\
\hline Total CNC machine cost & $€$ & 400,000 & 400,000 & 400,000 \\
\hline Total CNC machine cost & $€ / \mathrm{pc}$ & 1.24 & 8.47 & 0.77 \\
\hline CNC consumed electrical power & $\mathrm{kW}$ & 6.62 & 6.62 & 1.65 \\
\hline Hourly energy cost & $€ / \mathrm{kWh}$ & 0.27 & 0.27 & 0.27 \\
\hline Total energy cost & $€ / \mathrm{pc}$ & 0.17 & 2.03 & 0.03 \\
\hline Production volume & $\mathrm{pc}$ & 1 & 10 & 100 \\
\hline Total unit cost & $€ / \mathbf{p c}$ & 189.71 & 666.59 & 51.94 \\
\hline
\end{tabular}


Table 6: Total unit cost for AM with and without geometry optimization.

\begin{tabular}{|c|c|c|c|c|}
\hline & & $\begin{array}{c}\text { Hip } \\
\text { prosthesis }\end{array}$ & $\begin{array}{c}\text { Bottle } \\
\text { blowing mold }\end{array}$ & $\begin{array}{c}\text { Automotive } \\
\text { gear }\end{array}$ \\
\hline Hourly cost for CAM programming & $€ / \mathrm{h}$ & 40 & 40 & 40 \\
\hline Programming time & $\mathrm{h}$ & 2 & 4 & 0.5 \\
\hline Total CAM programming cost & $€$ & 80 & 160 & 20 \\
\hline Rough piece volume & $\mathrm{mm}^{3}$ & $\begin{array}{c}38,948.36 \\
(30,548.97) \\
\end{array}$ & $\begin{array}{c}4,089,818.53 \\
(3,207,830.37) \\
\end{array}$ & $\begin{array}{c}54,133.51 \\
(42,459.37) \\
\end{array}$ \\
\hline Rough piece weight & $\mathrm{kg}$ & $\begin{array}{c}0.31 \\
(0.24) \\
\end{array}$ & $\begin{array}{c}32.72 \\
(25.66) \\
\end{array}$ & $\begin{array}{c}0.43 \\
(0.34) \\
\end{array}$ \\
\hline Unit material cost & $€ / \mathrm{kg}$ & 3 & 3 & 3 \\
\hline Total material cost & $€ / \mathrm{pc}$ & $\begin{array}{c}0.93 \\
(0.73) \\
\end{array}$ & $\begin{array}{l}98.16 \\
(76.99) \\
\end{array}$ & $\begin{array}{c}1.30 \\
(1.02) \\
\end{array}$ \\
\hline CNC manufacturing time & $\min / \mathrm{pc}$ & 0.43 & 45.44 & 2.41 \\
\hline Worker time for manufacturing & $\min / \mathrm{pc}$ & 0.04 & 4.54 & 0.24 \\
\hline Worker time for machine set-up & $\mathrm{min} / \mathrm{pc}$ & 1 & 1 & 0.5 \\
\hline Hourly labor cost & $€ / \mathrm{h}$ & 20 & 20 & 20 \\
\hline Total labor cost & $€ / \mathrm{pc}$ & 0.35 & 1.85 & 0.25 \\
\hline Tool useful life & $\min$ & 35 & 35 & 35 \\
\hline Unit tool cost & $€ /$ tool & 100 & 100 & 100 \\
\hline Total tool cost & $€ / \mathrm{pc}$ & 1.24 & 129.84 & 6.87 \\
\hline Working hours per year & $\mathrm{h} /$ year & 3,840 & 3,840 & 3,840 \\
\hline CNC machine useful life & year & 15 & 15 & 15 \\
\hline Total CNC machine cost & $€$ & 400,000 & 400,000 & 400,000 \\
\hline Total CNC machine cost & $€ / \mathrm{pc}$ & 0.17 & 5.38 & 0.34 \\
\hline Speed SLM production & $\mathrm{cm}^{3} / \mathrm{h}$ & 25 & 25 & 25 \\
\hline SLM manufacturing time & $\min / \mathrm{pc}$ & $\begin{array}{c}93.48 \\
(73.32) \\
\end{array}$ & $\begin{array}{c}9,815.56 \\
(7,698.79) \\
\end{array}$ & $\begin{array}{c}129.92 \\
(101.90) \\
\end{array}$ \\
\hline SLM machine useful life & year & 8 & 8 & 8 \\
\hline Total SLM machine cost & $€$ & 500,000 & 500,000 & 500,000 \\
\hline Total SLM machine cost & $€ / \mathrm{pc}$ & $\begin{array}{c}25.36 \\
(19.89)\end{array}$ & $\begin{array}{c}2,662.64 \\
(2,088.43)\end{array}$ & $\begin{array}{c}35.24 \\
(27.64)\end{array}$ \\
\hline CNC consumed electrical power & $\mathrm{kW}$ & 0.16 & 0.16 & 0.04 \\
\hline SLM consumed electrical power & $\mathrm{kW}$ & 0.2 & 0.2 & 0.2 \\
\hline Hourly energy cost & $€ / \mathrm{kWh}$ & 0.27 & 0.27 & 0.27 \\
\hline Total energy cost & $€ / \mathrm{pc}$ & $\begin{array}{c}0.08 \\
(0.07) \\
\end{array}$ & $\begin{array}{r}8.87 \\
(6.96) \\
\end{array}$ & $\begin{array}{c}0.12 \\
(0.09) \\
\end{array}$ \\
\hline Production volume & $\mathrm{pc}$ & 1 & 1 & 10 \\
\hline Total unit cost & $€ / \mathbf{p c}$ & $\begin{array}{c}108.13 \\
(102.44)\end{array}$ & $\begin{array}{c}3,066.72 \\
(2,469.44)\end{array}$ & $\begin{array}{c}2,922.72 \\
(2,325.44)\end{array}$ \\
\hline
\end{tabular}

Note: Numbers in parentheses represent the values associated to the optimized geometry; they are specified only when they differ from those obtained for the manufacturing without geometry optimization. 


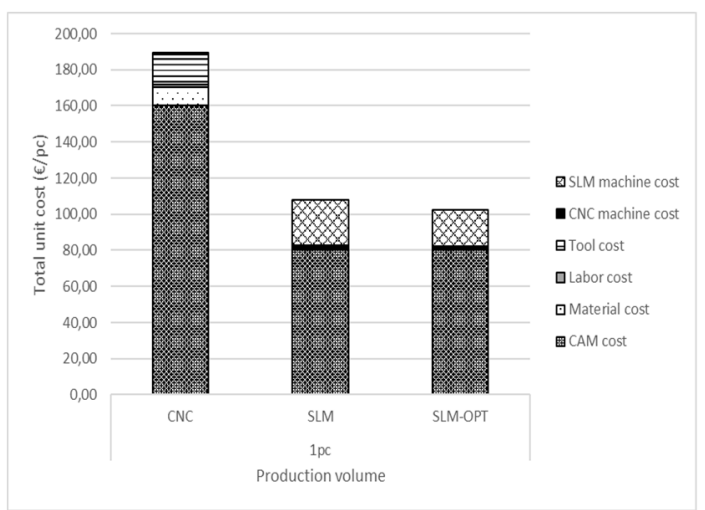

Figure 1: Total unit cost for hip prosthesis.

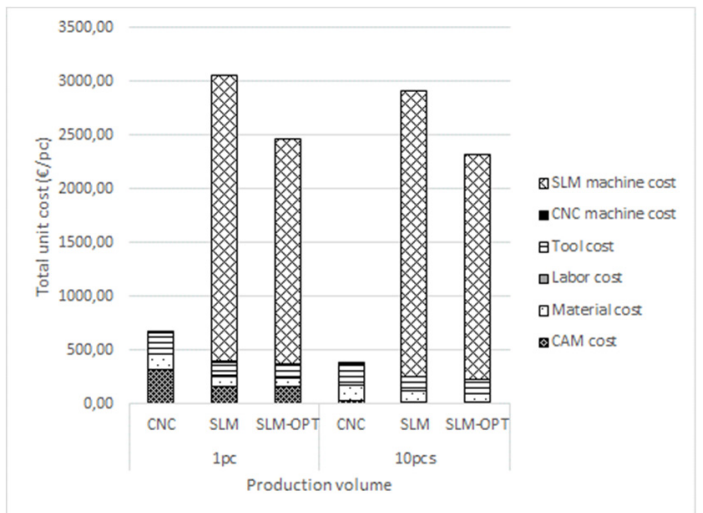

Figure 2: Total unit cost for bottle blowing mold at different batch sizes.

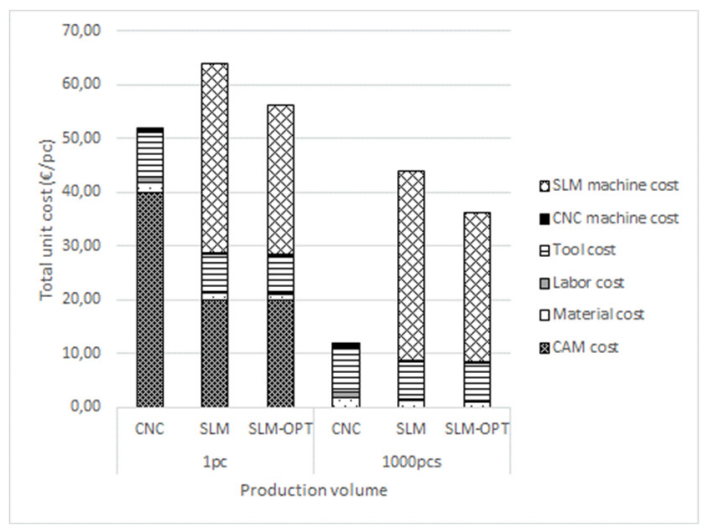

Figure 3: Total unit cost for automotive gear at different batch sizes. 
Table 7: Total manufacturing time (min) for a single piece production.

\begin{tabular}{lccccc}
\hline & Hip prosthesis & \multicolumn{2}{c}{ Bottle blowing mold } & \multicolumn{2}{c}{ Automotive gear } \\
\hline & $\mathrm{V}=1$ & $\mathrm{~V}=1$ & $\mathrm{~V}=10$ & $\mathrm{~V}=1$ & $\mathrm{~V}=1,000$ \\
\hline CNC & 250.73 & 553.16 & 121.16 & 66.67 & 6.73 \\
\hline SLM & 214.91 & $10,102.01$ & 9,886 & 162.83 & 132.86 \\
\hline SLM-OPT & 194.75 & $7,985.24$ & $7,769.24$ & 134.81 & 104.84 \\
\hline
\end{tabular}

Note: SLM-OPT refers to the use of AM with optimized geometry.

\section{DISCUSSION}

An analysis of the results shown in Tables 5 and 6 allows to make several observations. First of all, the CAM programming cost is significantly higher in traditional manufacturing. Therefore, in this context, the cost of a single piece is significantly influenced by the cost of programming, whose value reaches $84 \%, 48 \%$ and $77 \%$ respectively for hip prosthesis, bottle blowing mold and automotive gear. Obviously, when higher production volumes are hypothesized, this cost is spread among numerous pieces, making its effect on the total unit cost almost irrelevant. The result is that an increase of the production volume reduces the unit product cost in traditional manufacturing more than what happens in AM. Not by change, the traditional manufacturing becomes more and more convenient when numerous batches are considered. However, in general, we cannot state that the convenience of AM or not to AM strictly depends on the number of pieces to be produced, since three different situations emerge from the three product cases.

As for the prosthesis, AM appears the most convenient manufacturing solution because the programming cost of the CNC machine is very high, if compared to the other cost items.

For what concerns the bottle blowing mold, the amount of material needed for production and the resulting long SLM manufacturing times make this solution much more expensive than traditional manufacturing. The cost of the SLM machine is even $86 \%$ of the total unit cost of the product. This cost difference between the two solutions becomes even more significant as the production volume increases.

Finally, as regards the automotive gear, an intermediate situation emerges. The SLM machine cost is very high, but so does the CNC programming cost. Therefore, even if the latter is more convenient, the cost difference is rather limited, if compared to that of bottle blowing mold. However, by bringing the production volume to 1,000 pieces, the unit SLM machine cost remains the same, while that of CNC programming is significantly reduced, reaching an incidence lower than $1 \%$. Traditional manufacturing becomes therefore extremely convenient in this context.

Overall, making a purely economic evaluation, the analysis seems to suggest that the convenience of AM or not AM depends not only on the number of pieces, but also on the shape and size of the pieces to be produced. The hip prosthesis has a very small product volume: consequently, SLM machine cost and material purchase cost are not so high. The $\mathrm{CNC}$ programming cost is instead quite considerable, making the traditional manufacturing solution less convenient than the AM one. The bottle blowing mold has instead a very large product volume, which significantly increases the $3 \mathrm{D}$ printing times and, consequently, also the SLM machine cost. This latter, in particular, exceeds the programming costs of traditional manufacturing, making AM less convenient.

Obviously, this economic evaluation should be accompanied an analysis of the total time needed for manufacturing (see Table 7). As it could be expected, the total production times 
of bottle blowing molds and automotive gears are much higher in AM, especially when the volumes increase. Surprisingly, the production time of the hip prosthesis is instead shorter in the AM case. The reason for this result is similar to that proposed for the cost evaluation. The hip prosthesis requires indeed a significant $\mathrm{CNC}$ machine programming time, which accounts for a relevant part in the total manufacturing time.

\section{CONCLUSIONS}

This paper investigated the effectiveness of AM as alternative to traditional manufacturing by comparing mechanical properties as well as production costs and times of three components produced in the two manufacturing environments. The original designs of the three components were also optimized for AM by means of Finite Elements Simulations.

From the analyses, it emerged that the mechanical performances of additive-produced materials are comparable to those produced with traditional manufacturing. This element is therefore not particularly discriminating in the choice of one or the other technology. However, it is also true that AM has the advantage of being extremely versatile, allowing the creation of structures not producible otherwise. This opens the way for extreme optimization, such as that proposed in the first part of the paper.

Some differences exist instead in terms of production times and costs. In general, traditional techniques have higher fixed costs and shorter production times; they seem therefore more suitable for large batches. However, the analysis of components with very different structures suggested also that there is no general rule for the choice. For instance, contrary to all the expectations, the use of AM resulted to be less convenient for a bottle blowing mold, which has an average number of elements, than for automotive gear, whose elements are more numerous. The explanation lies in the fact that the mold has a simple geometry and a very high volume, which makes AM extremely slow and expensive.

Overall, it is possible to conclude that, to choose between the two alternative technologies, it is always necessary to analyze the specific characteristics of the item to be produced, in terms of shape, volume and structure. However, it is also worth highlighting that AM allows to create unique designs ensuring, for example, significant weight reductions or better weight distributions. Moreover, the lattice structures could be exploited to modify the heat transfer capability or to shift the eigen frequencies of the systems and, consequently, to improve the NVH (Noise, Vibration and Harshness) behavior. In this sense, if the design is optimized for AM, this new technology could really make the difference.

\section{REFERENCES}

[1] Kadir, A.Z.A., Yusof, Y. \& Wahab, M.S., Additive manufacturing cost estimation models: A classification review. The International Journal of Advanced Manufacturing Technology, 107(9-10), pp. 4033-4053, 2020.

[2] Costabile, G., Fera, M., Fruggiero, F., Lambiase, A. \& Pham, D., Cost models of additive manufacturing: A literature review. International Journal of Industrial Engineering Computations, 8(2), pp. 263-282, 2016.

[3] H'mida, F., Martin, P. \& Vernadat, F., Cost estimation in mechanical production: The cost entity approach applied to integrated product engineering. International Journal of Production Economics, 103(1), pp. 17-35, 2006.

[4] Mandolini, M., Campi, F., Favi, C., Germani, M. \& Raffaeli, R., A framework for analytical cost estimation of mechanical components based on manufacturing knowledge representation. The International Journal of Advanced Manufacturing Technology, 107(3-4), pp. 1131-1151, 2020. 
[5] Atzeni, E., Iuliano, L., Minetola, P. \& Salmi, A., Redesign and cost estimation of rapid manufactured plastic parts. Rapid Prototyping Journal, 16(5), pp. 308-317, 2010.

[6] Atzeni, E. \& Salmi, A., Economics of additive manufacturing for end-usable metal parts. The International Journal of Advanced Manufacturing Technology, 62(9-12), pp. 1147-1155, 2012.

[7] Hällgren, S., Pejryd, L. \& Ekengren, J., Additive manufacturing and high speed machining cost comparison of short lead time manufacturing methods. Procedia CIRP, 50, pp. 384-389, 2016.

[8] Lindemann, C., Jahnke, U., Moi, M., \& Koch, R., Analyzing product lifecycle costs for a better understanding of cost drivers in additive manufacturing. in 23rd Annual International Solid Freeform Fabrication Symposium - An Additive Manufacturing Conference, SFF 2012, pp. 177-188, 2012.

[9] Özbayrak, M., Akgün, M., \& Türker, A.K., Activity-based cost estimation in a push/pull advanced manufacturing system. International Journal of Production Economics, 87(1), pp. 49-65, 2004.

[10] Ruffo, M., Tuck, C., \& Hague, R., Cost estimation for rapid manufacturing - Laser sintering production for low to medium volumes. Proceedings of the Institution of Mechanical Engineers, Part B: Journal of Engineering Manufacture, 220(9), pp. 1417-1427, 2006.

[11] Ruffo, M., Tuck, C., \& Hague, R., Make or buy analysis for rapid manufacturing. Rapid Prototyping Journal, 13(1), pp. 23-29, 2007. 